Original Research

\title{
An Evaluation of a New Programme Training Mindfulness Teachers to Deliver Non-Eight Week Adapted Mindfulness-Based Interventions
}

\author{
Robert Marx ${ }^{1, *}$, Lisa Burroughes ${ }^{2}$
}

1. Sussex Partnership NHS Foundation Trust, Assessment and Treatment service, Brighton General Hospital, Elm Grove, Brighton, BN1 3EW, UK; E-Mail: robert.marx@sussexpartnership.nhs.uk

2. East Sussex County Council, County Hall, St Anne's Crescent, Lewes, East Sussex BN7 1UE, UK; EMail: Lburroughes@yahoo.com

* Correspondence: Robert Marx; E-Mail: robert.marx@sussexpartnership.nhs.uk

Academic Editors: Sok Cheon Pak and Soo Liang Ooi

Special Issue: Health Benefits of Meditation

OBM Integrative and Complementary Medicine 2019, volume 4, issue 1

doi:10.21926/obm.icm.1901009
Received: October 13, 2018

Accepted: January 29, 2019

Published: February 02, 2019

\begin{abstract}
:
Background: Training is generally not available for those wishing to deliver non 8 week Mindfulness Based Interventions (MBIs) adapted for specific contexts and populations. A new model for training in $\mathrm{MBl}$ s is developed with the following principle components: teaching on theory, participation in a practice, followed by teaching the practice and receiving feedback, and consultation and discussion of live mindfulness-based work.

Methods: A quantitative and qualitative evaluation is presented of the experience of the first cohort to complete the training.

Results: The results suggest considerable satisfaction with the training programme although recommendations for future changes to the training programme are made.

Conclusions: A framework is suggested that aims to balance the need to preserve the integrity and quality of mindfulness teaching with the need to be responsive and pragmatic to the needs and capacity of clinicians and community leaders who are increasingly using mindfulness in creative ways. Strengths and limitations of the evaluation are considered.
\end{abstract}

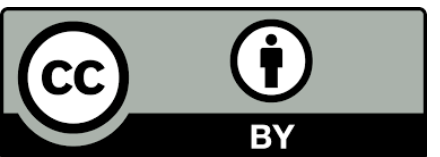

(C) 2019 by the author. This is an open access article distributed under the conditions of the Creative Commons by Attribution License, which permits unrestricted use, distribution, and reproduction in any medium or format, provided the original work is correctly cited. 


\section{Keywords}

Mindfulness; training; MBCT; MBI

\section{Introduction}

Demand appears ever growing for Mindfulness-Based Interventions (MBIs). Often this is in the form of established 8 week programmes such as Mindfulness-based Cognitive Therapy (MBCT) [1] and Mindfulness-Based Stress Reduction (MBSR) [2] for which there are recognised training programmes and training philosophies [3-5]. However, for the ever-growing number of people who are using adapted MBIs that are not MBCT, MBSR or other 8 week programmes, in their clinical or community work with various less-well researched populations, very little specific training is available.

In our mental health and learning disabilities organisation (an NHS Trust), we are aware of staff who are adapting mindfulness practices for use with a variety of different clinical groups - for example, running shorter adapted mindfulness groups for adolescents, groups for parents, using mindfulness exercises in groups for people with learning disabilities to help manage anger, adapted mindfulness practices for people who hear voices, mindfulness groups for people with early stage dementia and their carers, one off interventions using mindfulness in forensic or inpatient settings, within individual psychotherapy sessions or GP consultations, and for staff wellbeing and to reduce staff stress. Our own experience and that of others in the field [6-8] of adapting MBIs for populations with greater complexity or vulnerability has been that practices need to be more accessible and safer: often shorter, with more emphasis on grounding and stabilisation, with more concrete language and more heavily guided.

As we see it, there are two main potential hazards and problems in offering an adapted Mindfulness-Based Intervention (MBI) with these populations. First, people with inadequate training and experience in adapting MBIs with vulnerable clinical populations may seek to deliver MBIs $[9,10]$. Adapted mindfulness work often requires great skill, as it may be offered to complex populations with the potential for adverse reactions that may involve risk [11, 12]. Secondly, there is also often not yet a well-established protocol or evidence base for using MBIs with these groups. Without this foundation, the risk can be that the intervention is continued whilst being ineffective or even unhelpful.

Notwithstanding these reservations, we were faced with the question of how to respond to a rising tide of enthusiasm and appetite for adapted MBIs from both clinicians and patients. The minimum levels of training and experience often referred to in the literature [eg. 5] set an ideal to aim for but are not always implementable in practice for a number of reasons. Locally, with over 5,000 staff in our organisation, the reality is that it is impossible to track every mindfulnessinspired or mindfulness-derived intervention that each individual clinician uses. There is currently no national body set up with the teeth to register or de-register people who deliver 8 week programmes or MBIs. Individual clinicians chafe against challenges to their clinical autonomy and pressured managers may favour and support interventions that appear effective and cheap because they do not need to release their staff for lengthy trainings [13, 14]. As well as being impossible, it is not desirable to be policing all these MBIs when many of them in our experience 
are often requested by, and popular with, patients, enhance patient choice and small scale research [eg. 15] and audit [eg. 16] suggests they can be effective.

As Crane \& Reid state: “teacher training materials, programmes and resources... have not been developed to keep pace with the demand" [17] for good teachers of MBIs. The challenge as we saw it was therefore to try and channel the enthusiasm for MBIs into an organisational and training framework that ensures quality and safety. The three main arms of the strategy we used were governance, research and training.

Our first step was to develop clear governance for our organisation that was separate from the governance required to teach MBCT/MBSR for those who wanted to teach these adapted MBIs. Although national governance in the UK exists in the form of Good Practice Guidelines [18], these only apply to established 8 week programmes such as MBCT or MBSR and no such guidance exists at a national level for people wishing to deliver often shorter, adapted MBIs. We therefore developed governance criteria for our organisation that applies to clinicians delivering adapted MBIs that are not 8 week programmes. This governance specifies that where formal mindfulness meditation practice is an essential and regular component of the intervention, clinicians should have had the following: the training programme described in this paper or equivalent; a professional mental health training; an established, regular personal mindfulness practice; completion of at least one 8 week MBCT/MBSR course as a participant; on-going mindfulness supervision with an experienced mindfulness teacher; and CPD to support an up-to-date knowledge of the evidence-base for MBIs in the setting in which the intervention is being offered. To some people this appeared unnecessarily stringent; to others, it was unacceptably relaxed. However, it has been a pragmatic and realistic way to raise standards without strangling innovation through bureaucratic or idealistic requirements that may be impossible to apply because of limited availability of resources at an early stage of implementation. Rather, it seemed preferable to offer a relatively low hurdle that people might want to jump over, rather than an idealised high bar that people would simply avoid or resist.

Another essential aspect of our strategy has been to require people offering innovative MBIs for which there is limited evidence to rigorously evaluate what they are offering. Because clinicians and researchers have been working closely together in delivering MBIs in our organisation, we have been able to draw on research expertise to support safe innovation and generate new evidence.

The final element of our strategy and the main subject of this paper has been to offer a specialised brief training that would give clinicians delivering adapting MBIs the fundamentals of what we judged to be needed to work effectively and safely. The first cohort of the 'Training Programme in Adapted Mindfulness-based Interventions (MBIs) (for non 8 week programmes)' was delivered in 2016. As far as we are aware, this type of training has not been offered elsewhere, at least not in the UK. What follows is the description and evaluation of the programme.

\subsection{Development of the Training}

The training model had the following learning aims:

- To be able to teach a mindfulness-based approach in the clinician's setting.

- To be able to guide people in both formal and informal practices, adapting practices according to the relevant population and service. 
- To understand the rationale behind providing different mindfulness practices and some of the learning that is likely to be derived from them.

- To be able to teach in an embodied way, drawing on the teacher's experience of their own practice.

- To be able to express some of the attitudinal foundations of mindfulness, such as NonJudging, Non-Striving and Beginner's Mind; and keys aspects of the 'culture' of mindfulness-based approaches, such as seeing issues that arise as universal aspects of the human condition rather than as pathology.

- To understand, and be able to make some kind of assessment of, the risks of mindfulness practices with the teacher's participant population, and to be able to adapt practices accordingly.

- To have some knowledge of the evidence base for the use of mindfulness with the population being taught.

- To be able to help people explore their experience of a practice in a way that is congruent with mindfulness-based principles.

The training was open to staff in our own organisation and to people outside it who wanted to meet the above learning aims and were able to satisfy the following eligibility criteria. In order to apply for the training, applicants needed to:

- Have completed the 8 week MBCT/MBSR course as a participant.

- Have a regular mindfulness practice.

- Be able to describe appropriate ways in which they could use the training.

And for our own clinical staff applying, they needed to:

- Have a professional mental health training

- Have the support of their manager and clinical lead.

- Be in a role which allowed for the delivery of a mindfulness-based approach.

- Be in a service where there is either some evidence that the populations using that service can benefit from an $\mathrm{MBl}$; or where there were plans for a mindfulness intervention to be researched.

- $\quad$ work in a geographical area and service where there is currently limited provision of MBIs and/or where there were strategic Trust objectives for extending the delivery of particular MBIs.

\subsection{Components of the Training}

The main elements of the training comprised:

- Four and a half days of core teaching

- A one-day retreat.

- Personal mindfulness practice: as a rough guide, approximately 2 or 3 times per week of 20-30 minute practice.

- Recommended reading.

- Writing four 600 word reflective accounts throughout the training.

- An end of training programme tutorial.

There were also master classes and a conference available that were optional and additional elements of the training. Each training day had a similar structure, divided up each day into four sessions: 
1) One session always incorporated some element of didactic teaching on what we considered to be key themes in mindfulness teaching. This included the attitudinal foundations [2]; the role of embodiment and personal practice; common humanity/ kindness; metacognitive awareness/decentering; assessment and consideration of suitability for mindfulness interventions; safe practice and the risks of mindfulness with vulnerable groups; the evidence base; the use of materials, such as downloadable practices, making CDs, providing handouts. Prior to each teaching day, which were about two months apart from each other, trainees were given recommended reading on key mindfulness texts relating to the forthcoming subjects.

2) One session was always spent on one of the trainers leading the training group in doing a practice. The practices chosen tended to be similar to the type of practices they would mostly be leading: namely, relatively short (around 20 minutes) and with an emphasis on grounding and stabilisation rather than turning to difficulty. We started with body-based practice, then breathfocused, then movement/walking-focused, then mindfulness within everyday day life ('washing the dishes'). Prior to each teaching day, trainees were asking to download and regularly follow the same kind of practice themselves that we would be doing on the following teaching day. They were also asked to keep a reflective journal of their experiences of doing that practice, and of any teaching they might have done using that kind of practice, and to send it to the trainers two weeks in advance of the following teaching day.

3) After doing one of the practices on the teaching day, trainees were divided into small groups and asked to take turns to teach that practice to their small group. After teaching the practice, the trainee teacher and then the other trainees in the group and one of the trainers would give feedback. Trainees were often quite anxious doing this and so the emphasis was on positive feedback and encouragement. Ahead of the teaching day, we also asked trainees to practice leading the forthcoming practice and to record themselves doing so and to listen back to the recording, with the aim of both learning from doing and also of desensitizing the trainees to the anxiety they might feel on the teaching day.

4) One session was given over to providing consultation and case discussion in small groups on any mindfulness-based activity the trainees were already doing. Although the encouragement was to only provide mindfulness interventions after the training, in practice, many trainees had already been teaching mindfulness in various ways and so it was felt to be important to offer a space to discuss dilemmas and issues from this work.

There were four trainers and each of the full training days was led by two trainers with the other two assisting for the 'teachback' sessions (point 3 above) to allow for smaller groups, each held by a trainer.

The half training day was on identifying and working with trauma experiences in MBIs delivered by a trauma expert. It considered what trauma was, how it was re-experienced and within a mindfulness context, how it could be triggered and worked with. Due to the risk of MBIs triggering trauma-induced dissociative material [7] or other painful adverse reactions [19], sometimes termed 'backdraft' [20], we felt this was a key aspect of ensuring safety in teaching MBIs and was often an area that trainees were unsure about.

Whilst we would ideally have wanted trainees to be engaging in daily personal practice, and some did do this, we also wanted to set a reasonably realistic goal that could be achievable rather than one that would be unreachable and generate self-criticism. The requirement to attend one day retreat was an opportunity for participants to deepen their practice and their encounter with 
themselves. We usually hold two or three mostly silent day retreats each year and these are freely available to patients, ex-patients, staff and trainees. It is often on such days that people feel inspired through realising more keenly the benefit that the practice can bring them. The days can also invite participants - in this case trainees - to learn to be with more challenging aspects of themselves, which is invaluable for developing the confidence to help others' hold the pain that comes up in their own practice.

The personal mindfulness practice was considered to be foundational for teaching any MBI in an embodied way, rather than in a technical or intellectualised way. In delineating the essential aspects of a mindfulness-based program, Crane and colleagues asserted that "embodiment" is "a critical factor in enabling participants to move towards experiential (rather than conceptual) knowing of mindfulness." They explained "embodiment" as "a natural outcome of the teacher's intention to mindfully inhabit their experience in everyday life and in the Mindfulness Based Program classroom" [3] - which only happens through sustained personal practice. We made it clear throughout the training that we considered personal practice to be the cornerstone of any mindfulness teaching and that the professional delivery of an $\mathrm{MBI}$ is inseparable from the personal intention to bring awareness to all aspects of one's life.

The importance of reflection has been clear since Dewey [21] and Kolb [22]. Moon [23] gives many examples of how reflective writing can aid the learning process. The reflective writing in this training was a way of helping to embed learning from experience and keeping the learning personal and real. It also served as a way to maintain continuity and connection with the trainers across relatively well spaced out teaching days.

\subsection{Assessment of Trainees}

This was explicitly a formative rather than summative training programme and no formal assessment of competence was undertaken. This helped trainees to be vulnerable with what they did not know and wanted to explore, and to focus on developing and learning rather than passing. We used an individual end of training course tutorial with two of the trainers who used the Mindfulness Based Interventions Teaching Assessment Criteria (MBI-TAC) [24] as a guide for the tutorial discussion. The MBI-TAC is the most widely used assessment of teacher competence framework for MBCT and MBSR in the UK and increasingly beyond the UK. It has six domains thought to distil the most effective aspects of a competent mindfulness teacher which assess knowledge of the course curriculum, relational skills, embodiment of mindfulness, the way practices are guided, the way course themes are conveyed through interactive inquiry and didactic teaching, and the holding of the group learning environment. As the first and last of these domains specifically refer to the teaching of standardised 8 week mindfulness programs within a group setting, these were not considered so relevant for our trainees who were teaching non 8 week MBIs and not necessarily in a group. Therefore, domains 2-5 of the MBI-TAC were used to structure a discussion about the trainee's strengths, areas for further development, and the readiness of each trainee to lead mindfulness-based work. A page was then written up by one of the trainers summarising the tutorial themes and recommendations, and for trainees employed by our organisation, this was also copied to the trainee's manager and professional lead. In this way, managers and leads were aware of further training, supervision or other needs that might be 
helpful to put in place. Completion certificates were awarded for attending $80 \%$ of all the training components.

The remainder of this paper presents an evaluation of trainees' experiences of the training programme using quantitative and qualitative approaches.

\section{Method}

As this was evaluation data gathered within routine practice and constituted audit rather than research, no ethical approval was required. However, the work was conducted in accordance with the principles of the codes of conduct of our professional bodies.

\subsection{Trainees}

Twenty trainees in total started the training. Fifteen (75\%) were female. Fifteen (75\%) were qualified mental health professionals, comprising 9 clinical or counselling psychologists, 2 Occupational Therapists, 2 Community Psychiatric Nurses, 2 psychotherapists/counsellors, 2 directors of charities, 2 peer trainers with lived experience of mental health problems working for Recovery Colleges and 1 teacher. Trainees worked in a wide variety of settings: secondary (complex mental health) care (2), health psychology (2), research (2), private practice (2), charities (2), Recovery College (2), primary care (1), the prison service (1), adult learning disability services (1), child learning disability services (1) Child and Adolescent mental health services (1), community forensic services (1), in-patient services (1) and the Early Intervention in Psychosis service (1). Two dropped out, one due to health problems and the other due to financial pressures. Both of these were peer trainers in Recovery College.

\subsection{Measure}

Evaluation forms were given to each trainee at the end of the training programme. This form asked the following closed, Likert-scaled questions:

1. Overall, how useful was the training for your development as a mindfulness-based teacher?

(Not at all useful, Not that useful, Moderately useful, Useful, Very useful)

2. How relevant was the content of the training for your development as a mindfulness-based teacher?

(Not at all useful, Not that useful, Moderately useful, Useful, Very useful)

3. How would you describe the quality of the training delivery overall?

(Very poor, Poor, Acceptable, Good, Excellent)

4. How would you describe the quality of the training environment?

(Very poor, poor, Acceptable, Good, Excellent)

The following open-ended questions on the form then allowed people to expand on both their positive and negative experiences. Trainees were asked:

1. Overall, what did you find most useful, and why?

2. Overall, what did you find least useful, and why?

3. Can you say what struck you most about:

a. The teaching and learning style?

b. The content of the training? 
c. Your own practice in relation to being a teacher?

d. The administration and organisation of the training?

4. What do you feel is needed now to support your development as a mindfulness-based teacher?

5. Are there any other comments you would like to make about the training?

\subsection{Planned Data Analysis}

Descriptive statistics were used to present findings from the Likert-scaled questions given to the trainees at the end of the training. Eighteen completed the training and 16 completed the evaluations. Face to face interviews with five of the trainees were conducted a few weeks after the training had finished on the hospital premises where the researcher was based. The questions asked in the face to face interviews used similar wording to the open ended questions in the feedback forms but allowed the interview to probe each trainee for a more detailed exploration of their experience and to help the researcher interpret the responses received [25]. The material collected from the interviews and the open ended questions was analysed using content analysis $[26,27]$. General themes were identified for each question and the data were coded into content units based on the number of times specific words relevant to each theme were used. Illustrative quotes were then highlighted.

\section{Results}

\subsection{Responses to Closed, Lickert Scaled Questions}

As figure 1 shows, 94\% of the participants found the training very useful (81\%) or useful (13\%), one participant $(6 \%)$ said the training was moderately useful.

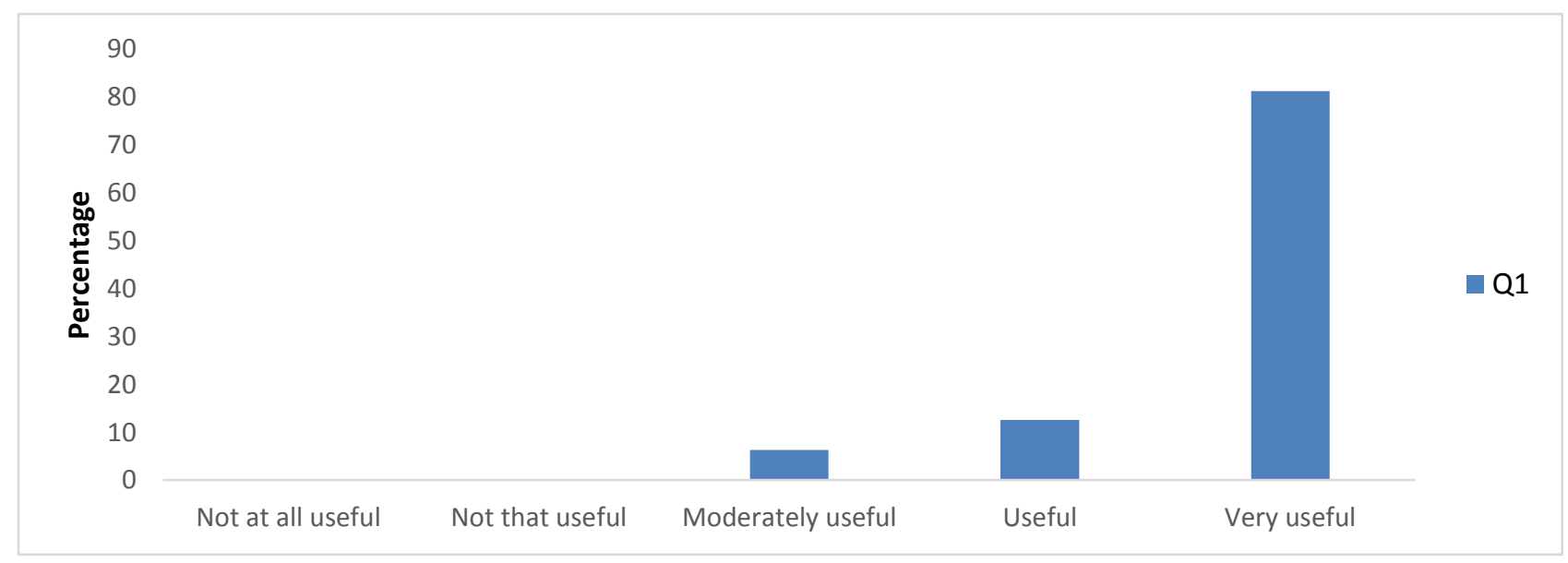

Figure 1 Responses on the usefulness of the workshops for their development as a mindfulness-based teacher (Q1). 
Figure 2 illustrates that $81 \%$ found the content of the training very relevant to their development as a mindfulness-based teacher, while a further $13 \%$ found it relevant. One participant (6\%) said the course content was moderately relevant.

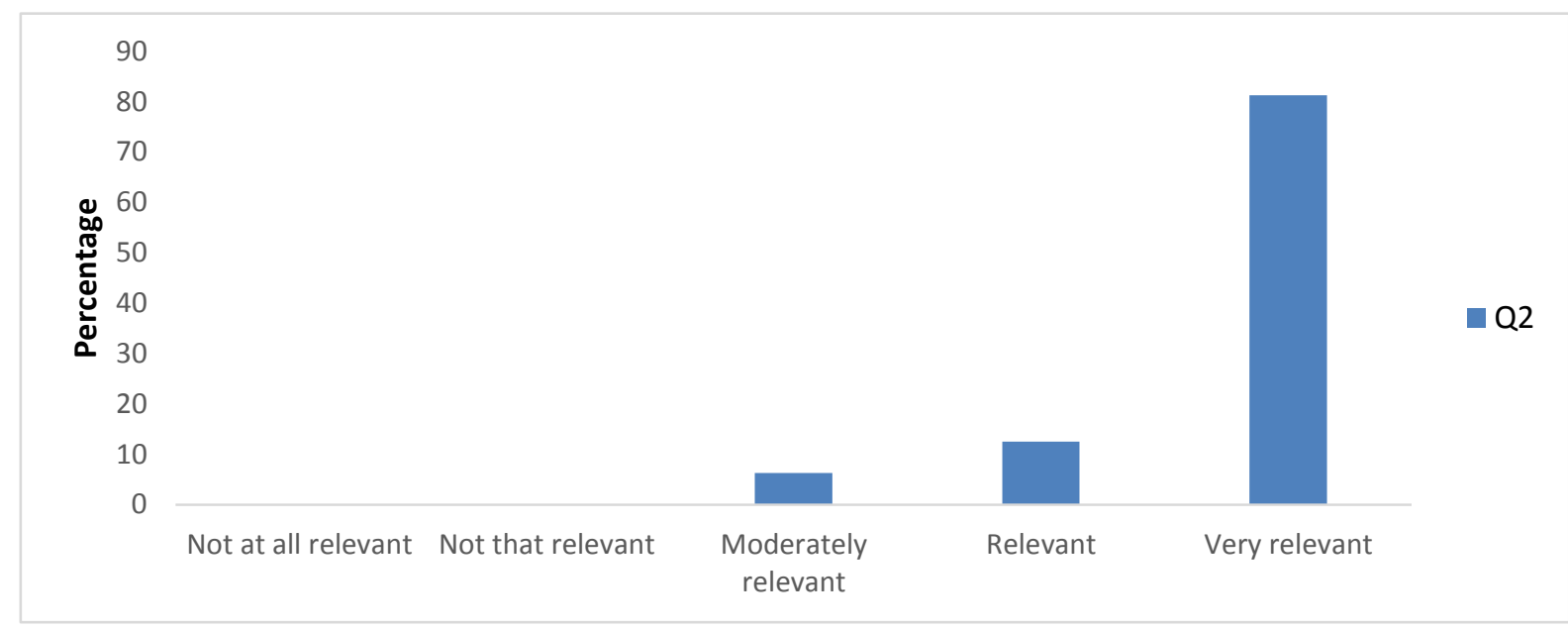

Figure 2 Responses for how relevant the training was for the development as a mindfulness-based teacher (Q2).

When asked about the quality of training delivery $81 \%$ said it was excellent, while a further $13 \%$ said it was good. Only one participant said the content was acceptable. All but one found the quality of the training environment to be either good (69\%) or excellent (25\%).

\subsection{Responses to Open Questions}

The material generated by open-ended questions on the forms given to trainees at the end of the training, was analysed, coded and categorised into themes and sub themes, and is presented in Table 1.

Table 1 Themes and sub-themes emerging from qualitative feedback $(\mathrm{N}=16)$.

\begin{tabular}{lll}
\hline Theme & Sub theme & Illustrative quote \\
\hline $\begin{array}{l}\text { What was most } \\
\text { useful }\end{array}$ & $\begin{array}{l}\text { Feedback on } \\
\text { practising teaching }\end{array}$ & $\begin{array}{l}\text { "The teaching practice was very useful, learning } \\
\text { from the feedback to myself and the others in } \\
\text { the small groups." } \\
\text { "I found all the resources very useful, I have } \\
\text { often gone back over the handouts, the } \\
\text { suggested reading." } \\
\text { "Doing the practices in small groups, with } \\
\text { Group work }\end{array}$ \\
& $\begin{array}{l}\text { everyone having an opportunity for guiding a } \\
\text { practice and inquiry, was a very helpful part of } \\
\text { the course." }\end{array}$ \\
& "The most useful overall on the MBA course was \\
& experience of the & sitting with, observing experiencing and listening
\end{tabular}


trainers

Learning about risks and safe practice

What was least useful

\section{Session on}

mindfulness and trauma

Insufficient individual feedback

Insufficient time to explore other adaptations

Timing of course

The teaching and learning style
A safe and supportive place to learn

Experiential learning carefully to the course teachers, taking in their seeds of wisdom, their advice and prompts. The tutors all so different have an immense amount of wisdom and experience, it's an honour to have these tutors look after you, an invaluable experience."

"How to teach safely (including the half day presentation on trauma and mindfulness) how to adapt the practices to our particular client group, case discussions."

"Though the talk was very good, interesting and informative and I learnt a lot, the link to a mindful approach I felt wasn't expressed clearly enough by the tutor so I didn't find the connection very useful."

"I would have liked having an individual tutorial half way through to get feedback and support identifying learning points or some feedback from the reflection essays."

"I would have liked more opportunity to think through the adaptation for our different client groups, for me, the child/LD population."

"It seemed as if there were some big gaps early on and then everything came by much quicker towards the end when I could have benefited form a bit more time to practice."

"What struck me most was the adaptability in the teaching. It offered students a friendly openness, honesty and invite to explore, nonjudgemental, non-demanding with an offer of gentle guidance, allowing space for each student to evolve, coming to their own or shared conclusion and understanding. Yet there was a firm grounding and structure to establish the ground work and a quiet demand to work at a certain level of competency."

"It was a really good mix of experiential discussion-based and theory-based learning. I liked having the 4 different teachers who have their own styles - but all modelling the qualities of a good mindfulness teacher!" 
The embodiment of mindfulness in the teachers

Calm and relaxed

Clear teaching structure

The content of the training

Structure
Trainees own practice in relation to being a teacher
More individual tailoring

The trauma content

The reading materials

Consistency in own practice

Focus in how to help clients

Developing

confidence

Embodiment of mindfulness

Reflection
"I really valued the embodiment of mindfulness by the trainers. The focus on inquiry, encouragement, experiencing whether in practice or our own teaching and humour."

"I found the teaching was lovely and calm."

"Good combination of theory and practice, clear teaching structure during the teaching days."

"Good it was very clearly broken down into the four different areas with the reflections and reading relating to each session."

"I would have valued some time thinking about teaching mindfulness in a one to one setting or within groups for the clients I work with."

"The teaching around the impact of mindfulness on traumatised people. I think before I felt as though there could be no possible contraindications for mindfulness or rather no risks involved in practicing it."

"I found the reading really enriched the teaching and it is something I will keep going back to."

"The course helped with consistency, regularity and focussing on practice."

"Doing the course has helped me become much more confident and clear in what I am trying to achieve when I introduce mindfulness to the clients I work with."

"The course helped me to focus my practice more and to develop confidence as a teacher."

"I have learned through the course that embodiment and authenticity are key to teaching."

"The sessions and reading and reflective accounts have helped me to reflect and appraise my own state of development as a mindfulness practitioner and teacher." 
The

administration

and organisation

of the training

What more is needed now
Good course

structure

Ending

Cost

Good course administration

Ongoing supervision

Further training opportunities

Networking with other teachers

Follow up with the group
"The mapping of the reading against the course material, which was a really good fit."

"I was also sad that at the ending all four teachers were not able to be there for the final part of the last day."

"Seemed expensive."

"The training was well organised. We were well informed about dates, times, what works was due and when."

"As it is early days for me, being able to have supervision of my ongoing work will be very important."

"I'd benefit from further support as a mindfulness teacher: attending future retreat days, keeping informed of upcoming mindfulness events and retreats in UK, and any related events at the SMC."

"It will be great if we can have a peer support group and learn from each other."

"Having a list of contact details of other group members for networking."

The results of the coded content analysis are summarised in the graphs below.

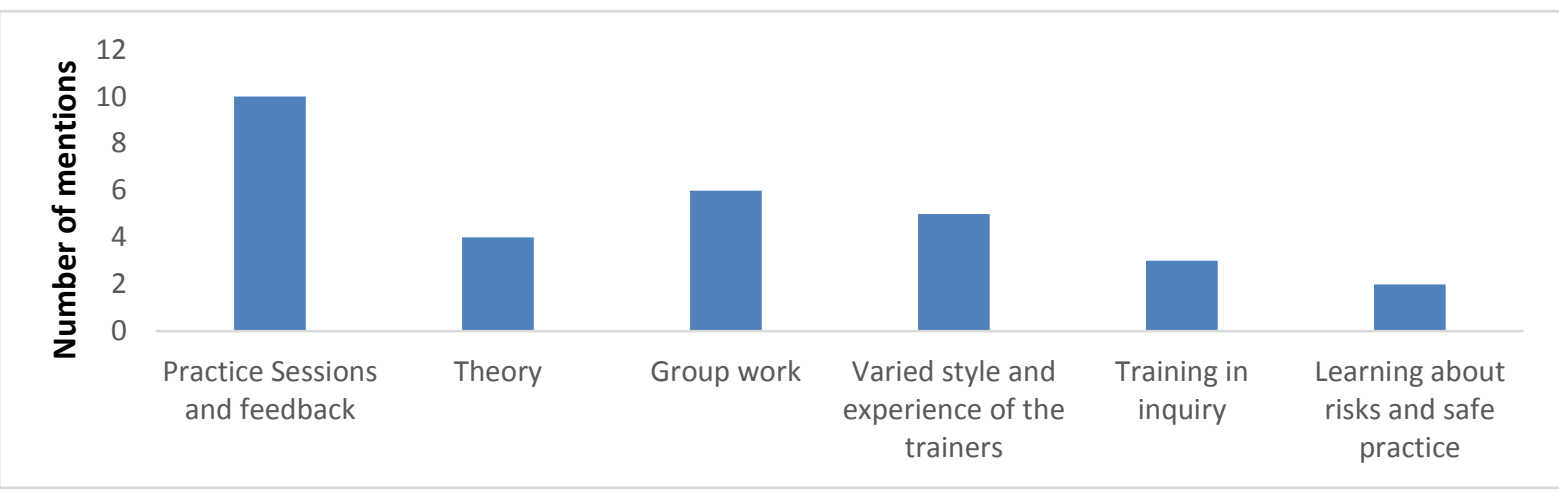

Figure 3 Respondents' experience of the most useful aspects of the course. 


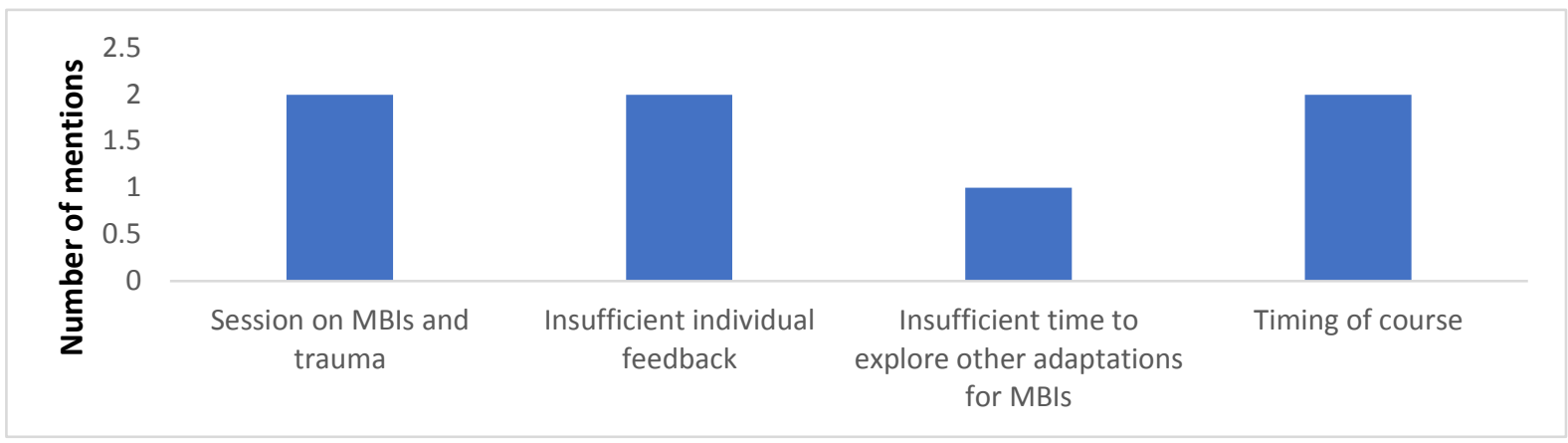

Figure 4 Respondents' experience of the least useful aspects of the course.

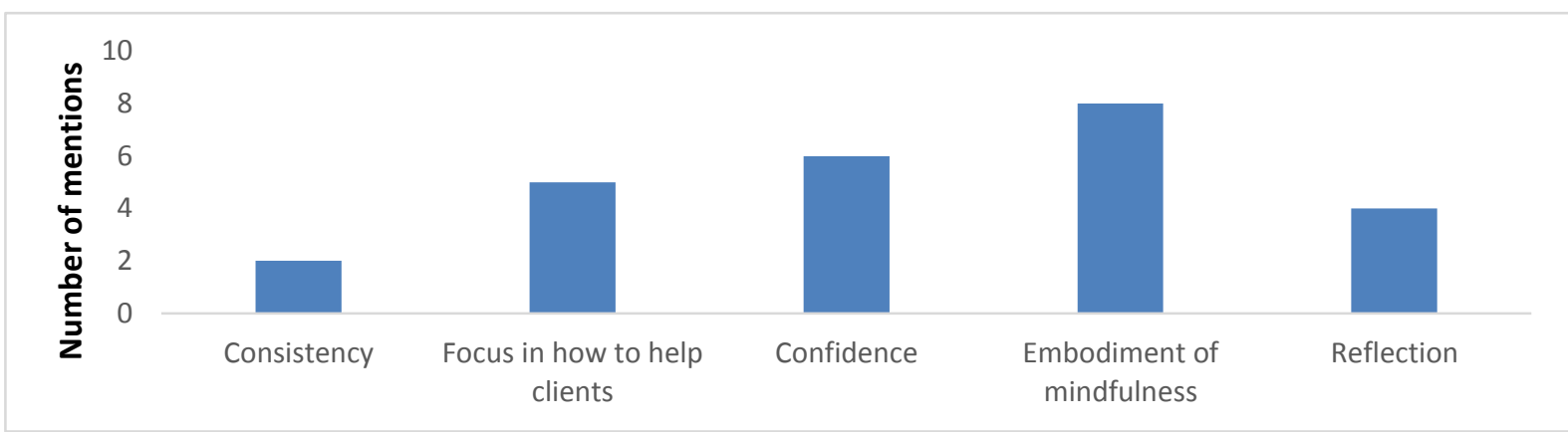

Figure 5 Responses for which aspects of the course resonated with respondents in relation to their own practice as a mindfulness teacher.

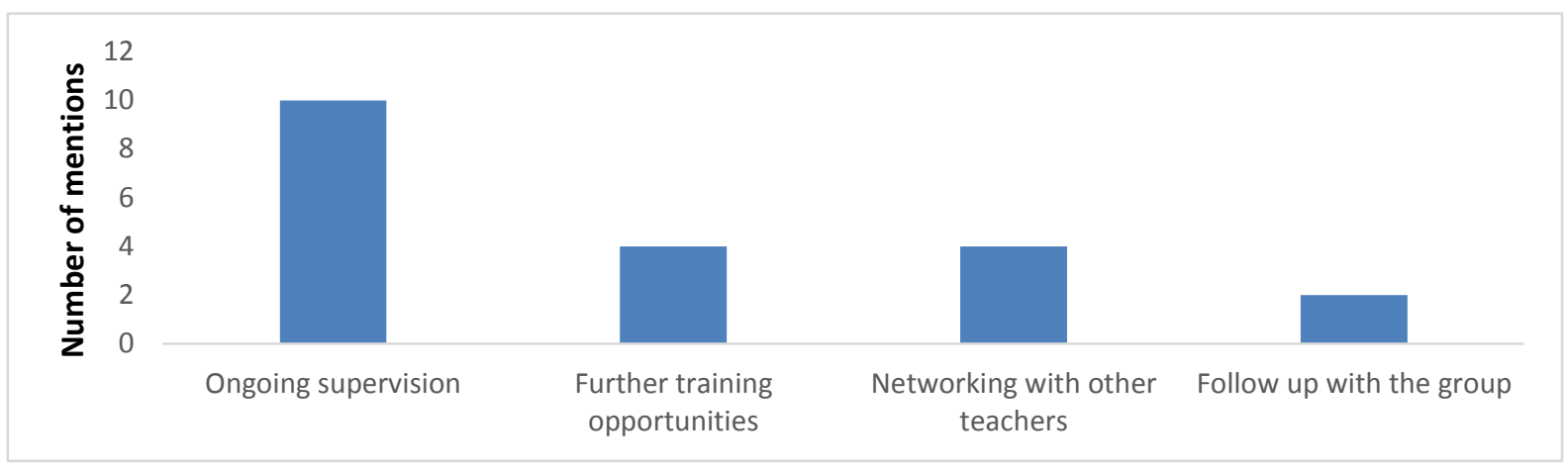

Figure 6 Responses for what respondents feel is needed now from the Sussex Mindfulness Centre to support their development as a mindfulness-based teacher.

\section{Discussion}

To our knowledge, this is the first such published evaluation of a training programme designed to facilitate the delivery of non 8 week MBIs. In terms of trainee satisfaction, the results from the Likert-scaled questions indicated a high degree of trainee satisfaction in the programme, including an expression of confidence in the programme's usefulness and relevance.

Results from the qualitative data suggested that trainees particularly valued the feedback on their teaching practice, which was a hallmark of the training, as well as the safe and nonjudgmental way in which it was offered. Often trainees commented that this component of the training was anxiety-provoking but very valuable for learning. Trainees also valued the theoretical 
underpinnings of mindfulness, an understanding of which is likely to help people teach an intervention that is more than just a technique. The combination of experiential and theoreticaldidactic teaching was valued and trainees seemed to appreciate both the way the training was structured and what they perceived to be the embodiment of the teachers and the variety represented by the different styles of the four core teachers. People seemed to value the teaching offered on assessment and risk as often people are not aware that MBIs can trigger distressing and potentially harmful responses in vulnerable groups $[7,12,19,20]$. The group context for learning was also a theme in the evaluation and seemed to be valued but also left some trainees feeling in need of individual input. There were mixed responses about the session on MBIs and trauma which was experienced as both insufficiently mindfulness-oriented and also useful in flagging contra-indications. Similarly, the teaching on how to adapt MBls to different populations was appreciated although some felt more could have been done in this area, particularly in adapting to the use of MBIs with children, people with learning disabilities and in individual therapy.

One issue for us to consider was any role we might have played in the non-completion of the training by two trainees who started it. Both trainees were peer trainers with previous lived experience of mental health issues working for the Recovery College. Although it seemed that the reasons for not completing were more personal than directly related to the training, we have considered whether there was any additional support we could have offered them to enable them to continue on the training. This is discussed further in the 'Recommendations' section.

The programme described, although short in terms of days of teaching, was spread across the best part of a year and included regular personal practice and written reflection to connect personal and professional learning and embed it. The task of the training programme was aided by taking on trainees who mostly had a good deal of both clinical and mindfulness experience before the course started. We also recognise that the learning is not complete when the training programme ends and that we need to provide opportunities for continuing supervision and continuing professional development (CPD) that enable mindfulness staff to keep growing. Such additional ongoing input is seen by the UK Network of Mindfulness-based Teacher Training Organisations as necessary for good practice for mindfulness teachers and is set out in their Good Practice Guidelines [18].

With this population of trainees who are mostly clinicians heavily committed elsewhere, and with the pressure on managers making it hard to release staff for training across the NHS [13, 14], there is always going to be a tension between creating a training that is long enough to offer meaningful input but short and affordable enough to actually ensure people sign up for it and can be released to do it. The market may change but at the moment, when it comes to learning to teach non 8 week adapted MBIs, the choice is generally between doing an extensive training to deliver MBCT or MBSR which is beyond the reach of many of the people who did our training, and which they would consider not appropriate for their purposes, or to continue to teach MBIs somewhat under the radar with no training at all. This kind of training that we feel has been carefully thought through and is connected with the heart of mindfulness, offers a pragmatic middle way that seems to have been valued by trainees, acceptable to managers and certainly better than attempting to offer MBIs with no training at all. 


\subsection{Recommendations for Future Training}

A number of recommendations emerge from this evaluation which we have now incorporated into the second cohort of this training, or which are planned for the third. These are outlined in the table below.

Table 2 Recommendations with actions.

\begin{tabular}{|c|c|c|}
\hline & $\begin{array}{l}\text { Recommendation } \\
\text { from } 1^{\text {st }} \text { cohort }\end{array}$ & Action taken for $2^{\text {nd }}$ cohort or planned for the $3^{\text {rd }}$ cohort \\
\hline 1 & $\begin{array}{l}\text { Re-think the } \\
\text { trauma session to } \\
\text { make it more } \\
\text { relevant to the } \\
\text { specifics of } \\
\text { encountering } \\
\text { trauma within a } \\
\text { mindfulness } \\
\text { context }\end{array}$ & $\begin{array}{l}\text { The session on MBIs and trauma is now taught by a trauma expert and } \\
\text { a mindfulness teacher with experience of trauma who can make the } \\
\text { content more mindfulness-specific. Material on assessing for risk and } \\
\text { suitability for MBls has also been linked in with this session. This } \\
\text { component has been further strengthened by adding a further half day } \\
\text { on the evidence base for MBls and on the experience of receiving MBIs } \\
\text { delivered by ex-patients. These topics support the theme of practising } \\
\text { safely and managing risk with vulnerable groups, using the knowledge } \\
\text { of both the research base and experience on the ground. }\end{array}$ \\
\hline 2 & $\begin{array}{l}\text { Enhance the } \\
\text { content on using } \\
\text { MBls with specific } \\
\text { populations }\end{array}$ & $\begin{array}{l}\text { We have also added an extra day to the training which allows us to } \\
\text { bring in mindfulness specialists for the populations that the trainees } \\
\text { are working with and to go into greater depth about the issues } \\
\text { encountered with these groups. Mindfulness specialists are available } \\
\text { to advise trainees working with people with learning disabilities, with } \\
\text { young people, in pain management, with complex mental health } \\
\text { problems and with staff. }\end{array}$ \\
\hline
\end{tabular}

3 Add components With improved scheduling, the two days we offer annually on these on psychological processes in MBIs and Buddhist foundations of mindfulness

4 Build the continuity of learning and support available to trainees across the year of training

5 Supporting trainees with two topics were easy to make available to this training group without adding to the cost of the training. There is also a mindfulness conference that is an optional component.

mental health and

We have plans to build a more effective online community to hold the continuity between group sessions and also to look into offering one or two individual tutorials during the programme to help support people, as needed. other

For applicants to the training with acknowledged mental health vulnerabilities, a more in depth assessment and selection process is required, primarily to ensure we have had a more detailed conversation about what those trainees need and how we can best 
vulnerabilities

6

Supporting
graduates from the
programme so that
they can offer safe
and good quality
MBIs after
graduating

Supporting programme so that they can offer safe and good quality graduating support them to complete. Periodic individual tutorials during the training year would also give more opportunity to address earlier any psychological pressures that might be impacting on these trainees completing the training.

One of the most important sources of support as an MBI practitioner is mindfulness-specific supervision. Practitioners of MBIs in our organisation are required to have mindfulness-specific supervision for their mindfulness work and all of our graduates have accessed this. There is however a need for more mindfulness supervision provision and we are taking steps to support some of our more experienced mindfulness teachers to train to become mindfulness supervisors. We are also working with the managers of those future supervisors to release them to supervise $\mathrm{MBI}$ practitioners who may not work in the service where the supervisor is based. We have so far supported an additional mindfulness supervisor to be trained with another about to start training.

\subsection{Strengths and Limitations of the Evaluation}

The evaluation was strengthened by giving weight to the actual experience of the trainees completing the training programme. Using both quantitative and qualitative methods increased the range of information we could draw on in relation to the training. The quantitative evaluation enabled us to specify the degree of trainee satisfaction with the programme and the qualitative evaluation allowed us to look in richer detail at trainees' experiences and in particular at what seemed to work and what needed revising. This triangulation of research methods enabled us to validate the findings and identify patterns in the trainees' experiences. The analysis was conducted by someone independent of the training programme, which helped to reduce bias and provided investigator triangulation $[28,29]$.

The current evaluation did not formally assess trainee competence in a way that would allow us to draw strong conclusions about the competence of trainees to deliver MBIs. As an assessment of competence tool, the MBI-TAC [24] does not completely translate into assessing the competence of those leading non 8 week MBls. The ethos of the training was also more formative than summative with a strong emphasis on being able to stumble safely while putting learning into practice without the potentially inhibiting effect of trainees knowing they were being formally assessed whilst doing so. On the other hand, some kind of more formal assessment process would give important information about the degree of success of the training.

This evaluation also did not explore the experience of graduates from this training one or two years post-completion to determine the lasting effect of the training and of post-training needs. Although there are often challenges in gathering data from alumni who have long since left, this data would be fairly easily extractable form our own employees who need to complete a periodic audit of the mindfulness supervision, CPD and personal practice that they have completed, and whether any support is required in any of these areas. This information could be incorporated into future research in this area. 


\section{Conclusions}

A first cohort completed a new training programme to deliver adapted MBIs. Graduates were positive about the training with high satisfaction levels and they particularly valued the opportunities to receive feedback on taught practices. They also highlighted a small number of areas to revise, notably a different version of the teaching on trauma, more specificity in teaching adaptations to particular clinical groups and contexts, and more opportunities for individual support. Many of these areas have since been addressed in the subsequent cohort of this training programme. Graduates also flagged the need for a supportive context to continue learning after the training had been completed, especially in the form of supervision and CPD. We hope that this training programme represents an additional option for training in delivering MBIs.

\section{Acknowledgments}

The authors wish to thank the other trainers who have contributed in different ways to the delivery of this training: Bridgette O'Neill, Taravajra, Karunavira, Nick Diggins, Kavyashri, Ann Pelling, Clara Strauss, Fergal Jones, Maeve Crowley, Ines Santos, Julia Racster-Szostak, Mike Hales, Helga Dittmar, Helen Leigh-Phippard, Tamsin Bishton, Susan Whiting, Martin Stent, Ruth Kendall, Brenda Davis, Caroline Windley, Pippa Menzies and Adrian Whittington, as well as all the trainees who participated so whole-heartedly in the training.

\section{Author Contributions}

RM led on the design of the training, and wrote all sections except the 'Results' section. LB collated the evaluations and analysed them in the 'Results' section.

\section{Funding}

No specific funding was accessed for this report. However, at the time, both authors worked for Sussex Partnership NHS Foundation Trust and some of the work took place within contracted hours for that employer.

\section{Competing Interests}

The authors have declared that no competing interests exist.

\section{References}

1. Segal ZV, Williams JMG, Teasdale JD. Mindfulness-based cognitive therapy for depression. 2nd ed. New York: Guilford Press; 2013.

2. Kabat-Zinn J. Full catastrophe living: Using the wisdom of your body and mind to face stress, pain and illness. New York: Delta; 1990. p31-40.

3. Crane RS, Brewer J, Feldman C, Kabat-Zinn J, Santorelli S, Williams JMG, et al. What defines mindfulness-based programs? The warp and the weft. Psychol Med. 2017; 47: 990-999.

4. Marx R, Strauss C, Williamson C. Mindfulness apprenticeship: A new model of NHSbased MBCT teacher-training. Mindfulness. 2015; 6: 253-263. 
5. Piet J, Fjorback L, Sanorelli S. What is required to teach mindfulness effectively in MBSR and $\mathrm{MBCT}$ ? Mindfulness and Buddhist-derived approaches in mental health and addiction. Gewerbestrasse, Switzerland: Springer; 2016. p. 61-83.

6. Dutton MA. Mindfulness-based stress reduction for undeserved trauma populations. Mindfulness-oriented interventions for trauma: integrating contemplative practices. New York: Guilford Press; 2015. p 243-272.

7. Treleaven DA. Trauma-Sensitive Mindfulness. New York: Norton; 2018. P. 87-149.

8. Williams $M$, Barnhofer T. Mindfulness-based cognitive therapy for chronic depression and trauma. Mindfulness-oriented interventions for trauma: integrating contemplative practices. New York: Guilford Press; 2015. p 91-101.

9. Crane RS, Kuyken W, Hastings RP, Rothwell N, Williams JMG. Training teachers to deliver mindfulness-based interventions: Learning from the UK experience. Mindfulness. 2010; 1: 7486.

10. UK Mindfulness All Party Parliamentary Group (MAPPG). Mindful Nation UK. 2015. Available from http://themindfulnessinitiative.org.uk/images/reports/Mindfulness-APPGReport Mindful-Nation-UK Oct2015.pdf

11. Baer R, Kuyken W. Is mindfulness safe? 2016. Available from http://oxfordmindfulness.org/news/is-mindfulness-safe/

12. Lomas $T$, Cartwright $T$, Edgington $T$, Ridge $D$. A qualitative analysis of experiential challenges associated with meditation practice. Mindfulness. 2015; 6: 848-860.

13. Greatbatch D. A false economy: Cuts to Continuing Professional Development funding for nursing, midwifery and the Allied Health Professions in England. Council of Deans of Health. 2016. Available from: http://www.councilofdeans.org.uk/wpcontent/uploads/2016/09/19092016-A-False-Economy-CPD-cuts-in-England-2016-17-.pdf

14. Merrifield N. Nurses being denied access to CPD 'due to staffing and funding pressures', warns RCN. Nursing Times. 2018. Available from:

https://www.nursingtimes.net/news/education/nurses-denied-access-to-cpd-due-to-staffand-funding-pressures/7024530.article

15. Singh NN, Lancioni GE, Winton ASW, Singh AN, Adkins AD, Singh J, et al. Mindfulness training assists individuals with moderate mental retardation to maintain their community placements. Behav Modif. 2007; 31: 800-814.

16. Fryer A, Strauss C. Evaluation of outcomes from sussex partnership mbct service user groups. Available from: https://sussexmindfulnesscentre.nhs.uk/research/outcomes-sussex/

17. Crane RS, Reid B. Training mindfulness teachers: Principles, practices and challenges. Resources for teaching mindfulness: An international handbook. Switzerland: Springer; 2016. p.121-138.

18. UK Network of Mindfulness-based Teacher Training Organisations. Good Practice Guidelines for teaching mindfulness-based courses. 2015. Available from: http://mindfulnessteachersuk.org.uk/index.html\#guidelines.

19. Lindahl JR, Fisher NE, Cooper DJ, Rosen RK, Britton WB. The varieties of contemplative experience: A mixed-methods study of meditation-related challenges in Western Buddhists. PLoS One. 2017. doi: 10.1371/journal.pone.0176239

20. Germer CK. The mindful path to self-compassion: Freeing yourself from destructive thoughts and emotions. New York: Guilford Press; 2009. 
21. Dewey J. How we think: A restatement of the relation of reflective thinking to the educative process. New York: D.C. Heath and Company; 1933.

22. Kolb DA. Management and the learning process. Calif Man Rev. 1976; 18: 21-31.

23. Moon JA. A handbook of reflective and experiential learning: Theory and practice. Abingdon: RoutledgeFalmer; 2004.

24. Crane RS, Soulsby JG, Kuyken W, Williams JMG, Eames C, Bartley T, et al. The bangor, exeter and oxford mindfulness-based interventions teaching assessment criteria (MBI-TAC). 2016. Available from: https://www.bangor.ac.uk/mindfulness/documents/MBI-TACMay2012.pdf

25. Torrance $\mathrm{H}$. Triangulation, respondent validation, and democratic participation in mixed methods research. J Mix Meth Res. 2012; 6: 111-123.

26. Krippendorff K. Content analysis: An introduction to its methodology. 2nd ed. Thousand Oaks, CA: Sage; 2004. p 413.

27. Weber RP. Basic content analysis. 2nd ed. Newbury Park, CA: Sage. 1990. p12.

28. Denzin NK. The research act: A theoretical introduction to sociological methods. New Jersey: Transaction Publishers; 1973.

29. Mertens DM, Hesse-Biber S. Triangulation and mixed methods research: provocative positions. J Mix Meth Res. 2012; 6: 75-79.

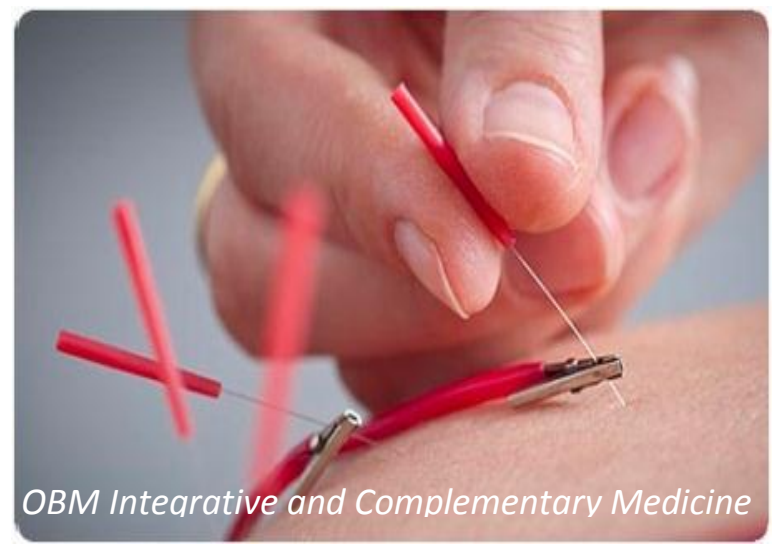

Enjoy $O B M$ Integrative and Complementary Medicine by:

1. Submitting a manuscript

2. Joining in volunteer reviewer bank

3. Joining Editorial Board

4. Guest editing a special issue

For more details, please visit: http://www.lidsen.com/journals/icm 